\title{
LITERATURA AFRO-BRASILEIRA: TEXTUALIDADE E CORPOREIDADE
}

\section{AFRO-BRAZILIAN LITERATURE: TEXTUALITY AND CORPOREITY}

Cátia Cristina Bocaiuva Maringolo*

Laísa Marra**
* Doutoranda em Letras - Estudos literários pela UFMG. Mestra em Estudos Literários pela UNESP. Membro do grupo de pesquisa NEIA/UFMG (Núcleo de Estudos Interdisciplinares da Alteridade).

Estadual do Ceará. Doutorand pela UFG. Membro do grupo de pesquisa NEIA/UFMG (Núcleo de Estudos Interdisciplinares da Alteridade).

ABSTRACT: The main objective of this article is to present a broad critic and historiographic overview about the Afro-Brazilian or Black literature concept, presenting and emphasizing some theoBlack literature concept, presenting and emphasizing some theo-
retical proximities and dissonances. With that, we expect to offer retical proximities and dissonances. With that, we expect to offer
a reflexive framework that challenges the hegemonic discourse about Brazilian literature aiming to open up, to strain the literary field, with the inclusion of new categories, texts and agents.

KEYWORDS: Afro-Brazilian Literature; Black Literature; Brazilian Literature; Black authorship
Sobre a escrita deste artigo: gostaríamos de aparecem na sequência acims (bas indo uma ordem alfabética. $O$ texto é colaborativo, fruto de nossos continuos debates, reflexões assim, năo é um artigo de primeira autora e segunda autora.

RESUMO: O principal objetivo deste artigo é apresentar um panorama crítico e historiográfico sobre a discussão do conceito de literatura afro-brasileira ou negra, apresentando e destacando convergências e divergências teóricas. Com isso, esperamos oferecer um arcabouço reflexivo que desafie o discurso hi monico sobre literatura brasileira, tentando ampliar, tensionar o agentes.

PALAVRAS-CHAVE: Literatura afro-brasileira; Literatura negra Literatura brasileira; Autoria negra. 


\section{Literatura afro-brasileira: considerações preliminares}

O conceito de literatura afro-brasileira, afrodescendente, afrodiaspórica ou negra está em ascensão desde a década de 1970, mas ainda não foi completamente institucionalizado e perma nece em tensão, reflexo dos próprios debates étnico-raciais, dentro e fora da academia. Essa tensão é tanto interna - como denota a multiplicidade de nomenclaturas e de polêmicas - como com o campo, este sim estabelecido, da literatura brasileira. Sobre a institucionalização, tomando o ano de 2020 como parâmetro, observa mos que não há no Brasil nenhuma linha de pesquisa dentro dos Estudos de Literatura Brasileira dedicada especificamente à literatura negra ou afro-brasileira. Assim, os pesquisadores que têm se dedicado a essas reflexões provêm da área de Teoria da Literatura, Teoria Literária, Estudos Culturais, Literatura Comparada etc., atestando o pouco diálogo dentro da área de Literatura Brasileira com as literaturas ditas minoritárias ou não ca nônicas.

Pensando nisso, este texto é um exercício de reflexão teórica e de crítica comparada na medida em que se propõe a investigar os conceitos de literatura negra ou afro-brasileira no bojo de sua elucubração e também em relação ao que se entende por litera tura brasileira. A leitura comparada se impõe quando a nalisa mos os textos críticos literários identificados ou auto-identificados com o projeto da litera tura afro-brasileira. Independentemente das diferenças conceituais, principalmente em torno do espinhoso problema da autoria, a literatura negra ou afro-brasileira é pensada sempre em termos de "resistência ao discurso dominante" (CUTI, 1985); de "valorização" de aspectos ligados ao negro e, portanto, tratados de maneira pejorativa pela literatura sobre o negro (PROENCA FILHO, 2004); de "resgate de uma memória esquecida" pela literatura e crítica literária brasileira (BERND, 1987, p. 18); e enquanto espaço quilombola (EVARISTO, 2010).

Segundo esse viés, autoras/es associadas/os à literatura afro-brasileira operam uma crítica a mecanismos de exclusão no campo literário, os quais estão em relação direta com os dilemas e impasses das nossas próprias relações étnico-raciais e sociais.

Os autores e autoras vinculados, de uma forma ou de outra, às heranças de extração a fricana têm contribuído para a permeabilidade do campo literário brasileiro já que suas opções estéticas e ideológicas alargam as margens de funcionamento do processo criativo. O que se espera, em contrapartida, é que a recepção da Literatura Negra e/ou Afro-brasileira, assim como de outras tendências literárias, nos permita desenvolver uma 
1. Texto retirado do portal literafro, cedido pelo autor. Disponivel em: <http://www. letras.ufmg.br/iterafro/artigos/ artigos-teorico-conceituais/1035 territorios-cruzados-relacoes-entree-ou-afro-brasileira $1>$. Aceso 25 abr. 2019.

2. De acordo com Priscila Elisabete Silva (2017) "branquidade" tradução de "whiteness" para o título brasileiro do livro organizado por Ware (2004), designa o mesmo que "branquitude". Cardoso (2017) traça o histórico desses vocabulos nas pesquisas feitas no Brasil, aponta que foram utilizados como sinônimos e que, náo obstante, uso mais frequente. Ainda segundo Cardoso, em 2005 Edith Piza propôs uma distinção conceitua desses termos - distinção com a qual Cardoso $(2017$, p. 48) não concorda por ser "uma ideia sem lastro na realidade. Assim sendo, falamos aqui de branquitude branquidade porque nos referimos aos vocabulos presentes no livro de (2004), respectivamente percepção crítica da vida social e literária do país. (PEREIRA, 2010, s. p.). ${ }^{1}$

A dificuldade, como aponta Edimilson de Almeida Pereira (2010), está em desenvolvermos na crítica literária novas percepções sobre a produção literária negra/afro-brasileira, uma vez que a abordagem hegemônica se constrói a partir da negação e exclusão da negritude pois se assenta na universalidade da branquitude/branquidade ${ }^{2}$. Grosso modo, branquitude é um conceito que designa identidade e privilégios brancos. Conforme Priscila Elisabete da Silva (2017, p. 27-28): "a branquitude é um construto ideológico, no qual o branco se vê e classifica os não brancos a partir do seu ponto de vista. Ela implica vantagens materiais e simbólicas aos brancos em detrimento dos não-brancos. [...] [A]presenta-se como norma, ao mesmo tempo em que como identidade neutra [...]." Nesse sentido, interessa-nos, para além de reivindicar uma negritude - uma condição negra na literatura -, reconhecer criticamente a branquitude quase que inerente à construção do campo literário brasileiro estabelecido.

O conceito de raça, como concebido historicamente - primeiro a partir de sua definição biológica, e posteriormente tornado verdade científica no século XIX demonstra uma fabricação, uma criação cujo objetivo era excluir as pessoas de origem africana e sujeitos não-brancos, justificando a escravização e a noção de superioridade e supremacia branca. Não obstante o fim da legalidade da escravização e o declínio da moda positivista, o conceito continua sendo de suma importância para compreendermos as relações sociais nas sociedades globalizadas contemporâneas. Carregada ainda de estereótipos e discursos pseudo-científicos, raça, categoria incontornável, é "um árbitro constante de diferença, bem como riqueza, classe e gênero" (MORRISON, 2017, p. 3, tradução nossa). ${ }^{3}$

Nesse contexto, destaca-se a criação, nos anos de 1970 em São Paulo, do Grupo Quilombhoje. Como o nome indica, o Quilombhoje foi criado visando a ser um lugar de encontro, resistência e produção antirracista voltado exclusivamente para autoras e autores negras/os. Com a criação desse "quilombo editorial" (RODRIGUES, 2017) ou seja, desse lugar contra-hegemônico em que escritores poderiam discutir as razões da imposição de uma subalternização literária, as dificuldades de publicação, e, por outro lado, estratégias de produção e publicação de uma litera tura que se apresenta racialmente marcada - surgem os Cadernos Negros, em 1978. Em seu primeiro número, os Cadernos Negros são apresentados da seguinte forma:
3. "[...] a constant arbiter of difference, as have wealth, class, 2017, p. 3). 
Os Cadernos Negros surgem como mais um sinal desse tempo de África-consciência e ação para uma vida melhor, e neste sentido, fazemos da negritude, aqui posta em poesia, parte da luta contra a exploração social em todos os níveis, na qual somos os mais atingidos. [...]

É a Diáspora Negra dizendo que sobreviveu e sobreviverá, superando as cicatrizes que assinalaram sua dramática trajetória, trazendo em suas mãos o livro (CN 1, p. 3 apud SOUZA, 2006, p. 106).

A menção da primeira edição dos Cadernos Negros à negritude, à diáspora negra e à África deve ser compreendida historica mente em relação ao movimento Negritude que, principalmente a partir da década de 1930, investiu diversos escritores negros, especialmente os que viviam fora de África, de uma compreensão globalizada e politicamente engajada da condição afrodiaspórica. Sabemos, por exemplo, que o conhecido Discurso sobre o colonialismo, publicado pela primeira vez em 1950 e depois, reeditado, em 1955, de Aimé Césaire (2010), junto com as publicações do senegalês Leópold Sédar Senghor fora $\mathrm{m}$ textos embrionários do que se denomina "movimento Negritude".

A celebração de culturas e origens a fricanas, entretanto, resultará na representação de uma África mítica, exótica e imaginária (FONSECA, 2014). Se por um lado os movimentos de negritude faziam, pela primeira vez, uma representação positiva e afirmativa das identidades negras, por outro lado, foram depois criticados por acionar os mesmos estereótipos e pré-conceitos que, em um primeiro momento, pretendiam subverter - o que, todavia, não nos permite minimizar a originalidade dos movimentos e a ênfase na conscientização política e crítica do artista negro. Nesse cenário, evidencia-se no Brasil o pioneirismo do Tea tro Experimental do Negro, fundado no Rio de Janeiro em 1944, em torno da figura de Abdias do Nascimento, enquanto um importante marco da expressão artística e política de sujeitos negros.

No âmbito das reflexões acadêmicas, conforme aponta Eduardo de Assis Duarte em "Entre Orfeu e Exu, a afrodescendência toma a palavra" $(2011, v .1)$ - texto introdutório da coletânea crítica Literatura e afrodescendência no Brasil, de que trataremos mais adiante -, o estudo sobre a presença do negro na literatura, seja enquanto autor(a) ou temática, é um fenômeno recente. Duarte (2011, p. 28) assinala como pioneiro o trabalho do francês Roger Bastide em $A$ poesia afro-brasileira, de 1943, e Estudos afro-brasileiros, de 1953, este último com escopo ampliado, que considerava também a atuação das pessoas negras na imprensa.

Depois, sublinhando a aparente falta de interesse da universidade brasileira pelo tema, Duarte (2011, p. 28) 
menciona os trabalhos dos estrangeiros brasilianistas Raymond Sayers, com O negro na literatura brasileira (de 1958) e Gregory Rabassa, autor de O negro na ficção brasileira (1965). Vale ressaltar que essas publicações e também o livro de Teófilo de Queiróz Júnior - O preconceito de cor e a mulata na literatura brasileira, publicado em São Paulo, em 1975 - focaram-se exclusivamente na problemática do negro enquanto tema literário, sem refletir sobre a autoria do sujeito negro, motivo pelo qual Duarte (2011) considera que a obra de Bastide permanecia singular.

\section{Literatura negra - o debate no centenário da abolição}

Com a ressalva de que a lacuna de estudos críticos sobre o negro e sobre a litera tura nacional já tinha sido apontada por Silvio Romero (1978), em seu ensaio de 1880 (texto esse que, não obsta nte, reproduz perspectivas racistas), como silenciamento objetivo e como sintoma do preconceito racial contra o negro; o panorama que se nos apresenta é o de uma esquivança do tema por parte dos críticos literários brasileiros (com raras exceções, como Queiróz Júnior e a revista Afrodiáspora, de 1977), situação que só começa a mudar a partir de 1970 e 1980.

Não é casual que justamente na década de 1980, especialmente em seus últimos anos, surjam trabalhos preocupados com a relação da pessoa negra e a literatura nacional, uma vez que o momento era de comemoração do centenário da abolição da escravatura e antecedido por uma série de movimentos coletivos em prol da investigação, produção e valorização do trabalho de artistas negras e negros. Esses movimentos, que se estendem pelo século $\mathrm{XX}^{4}$, são ações que marcam uma posição literária ímpar: a produção de literatura e crítica engajada com o combate do racismo estrutural e com o consequente papel de objeto relegado ao sujeito negro pela literatura.

Para que se tenha uma noção quantitativa desse momento emblemático, reproduzimos aqui alguns dos nomes mencionados por Zilá Bernd (1987, p. 19-20) - que publica uma série de estudos sobre literatura negra brasileira no final dos a nos de 1980 e começo dos anos de 1990 -, são eles: Miriam Mendes Garcia, A personagem negra no teatro brasileiro, de 1982; Três poetas da negritude, de 1981, e Três poetas baianos da negritude, de 1982, publicações do Centro de Estudos Afro-Orientais da UFBA; Zila Bernd, A questão da negritude (1984); Paulo Leminski, Cruz e Sousa, o negro branco, de 1982; Regis de Morais, Lima Barreto, o elogio da subversão, de 1986; Elisa Larkin do Nascimento, Dois negros literários, 1985 - os três últimos, com escopo menos abrangente que o dos primeiros, são estudos em que se destaca a questão racial de autores negros (o texto de Nascimento é
4. Por exemplo, os já mencionados Teatro Experimental do Negro.
EM TESE
BELO HORIZONTE
v. 26
N. 1
JAN-ABR. 2020
MARINGOLO; MARRA. Literatura Afro-brasileira: textualidade e corporeidade. P. 14-31 
5. O ensaio de Proença Filho fo depois modificado ligeiramente trajetória do negro na literatu brasileira (PROENÇA FILHO, 2004), versão essa que será examinada neste texto. sobre Luís Gama). Bernd (1987, p. 19) cita ainda Negritude: usos e sentidos, de Kabengele Munanga, mesmo esse sendo um trabalho de crítica antropológica, e não literária. Além desses, menciona mos Poesia negra no modernismo brasileiro de Benedita Damasceno (1988), que entende por poesia negra aquela que tematiza o negro ou traz para a poesia símbolos relacionados à afrodescendência - independente do pertencimento étnico-racial do escritor e de sua adesão ou crítica a estereótipos racistas.

Dentre os estrangeiros, em 1983 David Brookshaw publica Raça e cor na literatura brasileira. Outras pesquisas importantes são: Literatura e consciência, de Otávio Ianni, e O negro e a literatura brasileira, de Domício Proença Filho, e Introdução à literatura negra, de Zilá Bernd - os três de $1988^{5}$. Além disso, é preciso sublinhar a coletânea Reflexões sobre a literatura afro-brasileira, publicada pelo Quilombhoje em 1985. Dessa coletânea, destaca-se o texto de Cuti (1985): Literatura negra brasileira. Observe-se que já no título Cut marca uma diferença entre a literatura hifenizada com o prefixo afro, e a litera tura negra brasileira - diferença essa que se manterá no pensa mento do autor, que em 2010 lança pelo Selo Negro o livro Literatura negro-brasileira.

Das publicações elencadas no parágrafo a nterior, sobressaem-se os livros de Brookshaw (1983); o da própria Bernd, Negritude e literatura na América Latina (1987); e os de Proença Filho (2004) e Ianni (2011) como textos que tiveram maior impacto no período: segundo o Google Acadêmico $^{6}$, eles fora m citados 369, 284, 144, e 79 vezes respectivamente. Conjectura mos que isso se explique pelo caráter conceitual das indagações dos autores, sobre como equacionar literatura e raça/ etnicidade, o que os diferencia dos estudos que examinavam o tra tamento do negro enquanto temática ou estudavam a questão racial na obra de um determinado autor.

O brasilianista David Brookshaw (1983), além de criticar a escassa atenção que tanto os textos literários quanto os críticos dispensaram ao papel do negro nas Letras, traz na estruturação do seu livro uma diferenciação entre literatura produzida por brancos e literatura produzida por negros. A primeira parte de Raça e cor na literatura brasileira (BROOKSHAW, 1983) é intitulada O escritor branco; e a segunda, $O$ escritor negro. A primeira trata principalmente dos estereótipos racistas e a segunda, da conscientização racial do negro.

Diferentemente de Brookshaw (1983), cujo trabalho prioriza a compilação de autores e personagens negros e um balanço da relação da literatura canônica brasileira com a questão racial, os trabalhos de Zilá Bernd (1987, 1988, 2011 [1992]) procuram conceituar o que seria uma "literatura negra". Para a autora, o conceito dependeria de "uma 6. Disponível em: <https://
scholar.google.com.br/citations ?user= yiy KYbQAAAAJ\&hl=ptBR>; <https://scholar.google.com. $\mathrm{br} / \mathrm{scholar}$ ?hl=pt-BR\&ass dt $=0 \% 2 \mathrm{C}$ $\& q=$ david + brookshaw $\& b \operatorname{btn} G=>$ Acesso em: 11 set. 2018.
EM TESE
BELO HORIZONTE
v. 26
N. 1
JAN.-ABR. 2020
MARINGOLO; MARRA. Literatura Afro-brasileira: textualidade e corporeidade. P. 14-31 
articulação entre textos dada por um certo modo negro de ver e de sentir o mundo" e da "utilização de uma linguagem marcada tanto a nível do vocabulário quanto dos símbolos usados pelo empenho de resgatar uma memória negra esquecida" (1987, p. 18). Isto é, a literatura negra seria marcada por uma perspectiva racial (negra) que se faria notar no âmbito formal, o qual seria orientado pelo resgate da memória negra.

Bernd (1987) refuta a associação entre perspectiva "certo modo negro de ver e de sentir o mundo" (1987, p. 18) - e autoria negra por dois motivos: primeiro, nas palavras da pesquisadora, pois a "epidermização da questão feita por alguns críticos nos parece inoperante por não haver nenhuma relação entre o fato de se pertencer a uma determinada etnia e a estruturação da sensibilidade" (1987, p. 16); segundo, pela "dificuldade em saber, num país mestiço como o Brasil, quem é negro e quem não o é" (1987, p. 19). De fato, é preciso sempre enfatizar que as diferenças raciais não são inerentes aos sujeitos e nem tampouco aos textos; porém isso não é o mesmo que admitir que, embora essas diferenças seja m histórica e culturalmente construídas, elas não existam.

A recusa em tratar da autoria é uma marca do texto de Bernd (1987; 1988), que contorna a questão de maneiras contraditórias, ora admitindo que " $40 \%$ da população é constituída por negros e mulatos" (1987, p. 14); ora, como vimos, afirmando a dificuldade brasileira de se saber "quem é negro e quem não é" (1987, p. 19) - embora os estudos da branquitude/ branquidade venham desmistificando essa dificuldade como estratégia retórica para a manutenção de privilégios raciais brancos (MÜLLER; CARDOSO, 2017; WARE, 2004).

De modo geral, a autora resolve o problema da equação perspectiva/ autoria pela ideia do sujeito de enunciação textual - um sujeito que fala sobre negritude. Para Bernd é literatura negra aquela em que há "um eu enunciador que se quer negro, que reivindica sua especificidade negra" (1987, p. 16). Bernd parece apontar que o sujeito da enunciação mascara uma categoria sociológica, como se existisse uma cisão entre texto e realidade histórica. $\mathrm{O}$ maior problema dessa afirmação é deixar de perceber que existe uma realidade empírica que categoriza sujeitos de acordo com preceitos raciais, sociológicos, sexuais, de gênero, que exclui e inclui determinados discursos do campo literário canônico a partir de uma materialidade corpórea.

Domício Proença Filho, autor de trabalhos muito conhecidos pela crítica especializada, qua is seja m, $O$ negro a literatura brasileira (1988) e A trajetória do negro na literatura brasileira (2004), tem uma concepção da associação entre literatura e negritude parecida com a de Bernd (1987; 
1988). Também para ele deve prevalecer nessa discussão o elemento da perspectiva, ou em suas palavras, um "posicionamento engajado" (2004, p. 176) da obra. Por ser esse um critério basilar, na compilação de autores e obras que passariam de alguma forma pela questão racial, o autor procura discriminar critérios para se pensar "literatura sobre o negro, de um lado, e literatura do negro, de outro" (PROENÇA FILHO, 2004, p. 161, grifo do autor). Para tanto, Proença Filho (2004) apresenta dois sentidos, um restrito e outro amplo, a tribuídos à expressão literatura negra, vendo como "perigosa" a aceitação do sentido restrito "uma literatura feita por negros ou descendentes assumidos de negros” (2004, p. 185) -, pois a miscigenação no país tornaria essa tarefa "no mínimo complexa":

O risco da adjetivação limitadora reside, segundo penso, no explicável mas perigoso empenho em situar radicalmente uma autovalorização da condição negra por emulação, equivalência ou oposição à condição branca, colocação no mínimo complexa no caso brasileiro, diante até da dificuldade de se estabelecer limites entre uma e outra no miscigenado universo da cultura nacional. Mesmo porque as distinções nessa área costumam apoiar-se na cor da epiderme e na estereotipia sedimentada.

Nesse sentido, o opositor não é o brasileiro branco, mas o brasileiro preconceituoso. O esquecimento desta distinção implica não considerar o apoio dos aliados relevantes na busca do espaço negado. (PROENÇA FILHO, 2004, p. 186, grifo nosso).

Nessa citação direta é possível enxergar um pressuposto próximo ao apresentado por Bernd (1987) como justificativa do problema de se postular a autoria do sujeito negro como uma condição para o conceito de literatura negra. Para Proença Filho (2004), como para Bernd (1987), há uma complexidade imposta pela miscigenação à diferenciação racial no sentido de que o fenótipo seria uma variável muito imprecisa. Essa imprecisão, para Proença Filho (2004, p. 186), dificultaria a té mesmo uma radical autovalorização da condição negra.

A polêmica da questão pode ser ilustrada pela inserção que faz o referido autor do romancista branco João Felício dos Santos como possível integrante da literatura do negro (devido à valorização do negro em seu texto) e, paralelamente, pela exclusão de Machado de Assis dessa mesma categoria: "De minha parte, entendo que a literatura machadiana é indiferente à problemática do negro e dos descendentes de negro, como ele" (2004, p. 172). No entanto, vale ponderar que foi justamente a leitura contemporânea de Machado de Assis como um autor negro que possibilitou examinar os aspectos raciais de seus narradores brancos. Por essa ótica, de uma maneira própria e consciente da 
diferença imposta aos negros pela escravização, a narrativa de Machado de Assis teria emulado crítica e ironicamente a perspectiva da hegemonia branca, levando em conta sua especificidade no contexto brasileiro (DUARTE, 2009). Por fim, cabe enfatizar a recusa de Proença Filho de falar em uma literatura negra: "Entendo que é muito mais pertinente e apropriado, por força mesmo do propósito de afirmação da etnia, que, em lugar de litera tura negra se defenda a referência à presença do negro ou da condição negra na literatura brasileira" (2004, p. 188, grifo do autor).

Publicado em 1985 pelo Quilombhoje, numa coletânea crítica intitulada Reflexões sobre a literatura afro-brasileira, o breve ensaio do escritor, poeta, ensaísta e crítico Cuti, pseudônimo de Luiz Silva - Literatura negra brasileira: notas a respeito de condicionamento - ta mbém enfoca a consciência como traço primordial da literatura negra brasileira: "É a poesia feita pelo negro brasileiro consciente" (1985, p. 15). Nas palavras de Cuti, a produção literária do negro brasileiro

[...] tem se constituído numa resistência ao discurso dominante. Este, com todos os recursos de que dispõe, confunde, tergiversa e se reflete no texto literário. Já vimos o quanto vem tendo eficácia nas grandes obras nacionais (assim consideradas quase sempre sem nenhuma alusão às posturas anti-negras). (CUTI, 1985, p. 19-20)

Diferentemente de Bernd (1987; 1988) e Proença Filho 2004), Cuti (1985) associa a consciência racial com a experiência de vida dos escritores negros, evidenciando a autoria como um dos critérios definidores da literatura negra. Além disso, Cuti (1985) é mais enfático no argumento de que essa literatura se faria não só paralela mente à chamada literatura brasileira, mas numa relação de resistência a ela.

\section{Século XXI: literatura afro-brasileira como um con-} ceito em construção

No século XXI, expandindo o primeiro ensaio publicado em 1985, Cuti reflete (2010) sobre a possível recepção de leitores e críticos literários negros como um fator social e histórico indissociável de uma estética abertamente negra. Se, por um lado, o público não pode se fixar como categoria para conceituar literatura afro-brasileira enquanto estética ou gênero; por outro, é fa tor que a historiciza. De fato, nos Estados Unidos do século XIX, por exemplo, o contexto histórico e social marcado pelo protestantismo do público leitor costuma ser associado pelos historiadores e críticos literários ao tipo de abolicionismo que defendia a instrução da população negra e que, portanto, foi importante para o 
7. A maior parte dos estudos sobre slave narratives está publicada em inglês. Para mais detalhes sobre os processos de surgimento, consolidaçăo e publicação das narrativas, sugere-se consultar a antologia critica The Cambridge Slave Narratives (FISCH, 2007). gênero conhecido como slaves narratives (GOULD, 2007). Nesse sentido, é pertinente a interpretação feita por Cuti (2010) acerca da importância da recepção de um público, tanto virtual ou utópico quanto histórico, para a ascensão de uma perspectiva negra na literatura.

Acredita mos que isso não significa, no entanto, que a potencial recepção seja uma causa da origem da literatura negra e nem mesmo uma categoria definidora, mas apenas um entre outros fatores históricos. Se pensarmos novamente nas slave narratives, mesmo sendo possível estabelecer uma nítida relação entre público leitor e publicações, se não fossem os movimentos abolicionistas organizados, detentores dos meios de produção e do capital financeiro dificilmente teria sido possível que pessoas negras libertas publicassem (auto)biografias ${ }^{7}$.

Se os anos de 1980 e o final do século XX foram marcados por debates, reflexões e discussões sobre a literatura afro-brasileira, e sobre negritude a partir da consolidação e emergência de uma multiplicidade de movimentos negros organizados no Brasil, os anos 2000 presenciaram um marco nos estudos literários sobre literatura afro-brasileira, isto é, a coletânea Literatura e afro-descendência no Brasil uma antologia composta por 4 volumes publicados entre 2011 e 2014 (DUARTE, 2011). Fruto de um longo trabalho historiográfico, etnográfico, crítico e enciclopédico, os volumes mapeiam a tradição da escrita de sujeitos negros no Brasil do século XIX aos anos 2000

A publicação da antologia, sem antecedentes no Brasil, e o portal virtual literafro, projetos que contaram com a colaboração significativa de vários/as pesquisadores e pesquisadoras do país e do exterior, demonstram a consolidação dos estudos literários afro-brasileiros em uma academia marcada por sua palidez crítica e estética. Assim, a justificativa da ausência de escritoras/es negras/os nos manuais de literatura, que poderia ser percebida enqua nto impossibilidade e/ou incapacidade de produção literária pela população negra, é fortemente refutada pela antologia, que abrange uma grande quantidade de publicações, a maior parte das quais raramente mencionada nos livros de literatura brasileira.

No a rtigo Literatura afro-brasileira: um conceito em construção, Duarte (2007), anteriormente à organização e publicação da antologia, questiona qua is fatores diferenciariam a escrita afro-brasileira da escrita brasileira. Se é possível a firmar que existem diferenças, quais seriam e como poderíamos mapeá-las para possibilitar uma melhor compreensão e análise dessas produções.

Para o pesquisador, cinco fatores diferenciariam a literatura afro-brasileira da brasileira, sendo eles: temática, na
EM TESE
BELO HORIZONTE
v. 26
N. 1
JAN.-ABR. 2020
MARINGOLO; MARRA. Literatura Afro-brasileira: textualidade e corporeidade. P. 14-31 
esteira de reflexões trazidas por Ianni (1988); autoria; ponto de vista, com base nas contribuições de Bernd (1988) sobre uma discursividade especificamente negra; linguagem e público. A partir da análise desses cinco fatores, Duarte enfatiza que assim

[...] temos uma produção que está dentro da literatura brasileira, porque se utiliza da mesma língua e, praticamente, das mesmas formas, gêneros, processos e procedimentos de expressão. Mas que está fora porque, entre outros fatores não se enquadra na "missão" romântica, tão bem detectada por Antonio Candido, de instituir o advento do espírito nacional. Uma literatura empenhada, sim, mas num projeto suplemen $\operatorname{tar}$ (no sentido derridiano) ao da literatura brasileira canônica: o de edificar, no âmbito da cultura letrada produzida pelos afrodescendentes, uma escritura que seja não apenas a sua expressão enquanto sujeitos de cultura e de arte, mas que aponte o etnocentrismo que os exclui do mundo das letras e da própria civilização. Daí seu caráter muitas vezes marginal, porque fundado na diferença que questiona e abala a trajetória progressiva e linear da historiografia literária canônica. (DUARTE, 2007, p. 10)

A noção de literatura afro-brasileira como um campo literá rio dentro e fora da literatura brasileira é frutífera, pois acreditamos que aproxima a discussão conceitual desses dois campos não somente porque aquela literatura é tida como uma ramificação desta, mas porque os problemas são a nálogos: existe algo de inerentemente diferente na literatura brasileira? E na literatura afro-brasileira? Nos dois casos, parece desconfortável admitir que o acaso do nascimento do(a) a utor(a) é o fator primeiro e basilar que será articulado a outras categorias, como o uso de um mesmo idioma.

Com isso, percebemos que a literatura brasileira, enqua nto campo literário restritivo, é também regida por uma dinâmica que tem como eixo central justamente o critério mais acidental: o nascimento de um sujeito num dado espaço geográfico do globo. Isso vale ta mbém para as chamadas literaturas regionais, subcampos da literatura brasileira: literatura mineira, goia na, gaúcha. Não obstante o desconforto em ter que operar com um critério tão fortuito, aceitamos o essencialismo da naturalidade brasileira porque sabemos que embora não se possa separar biologicamente a raça humana entre chilenos e argentinos, franceses e angolanos, essa separação é uma construção histórica com efeitos bastante concretos. Por essa via voltamos a um dos maiores problemas do conceito de litera tura afro-brasileira, a autoria. 


\section{Autoria e lugar de fala: textualidade e corporeidade}

Nesse sentido, da autoria, é pertinente pensarmos na combinação dessa categoria com outras, como proposto por Duarte (2007), e especialmente no conceito de escrevivência, como proposto por Conceição Evaristo (2008). Para além de julgamentos de valores literários ou estéticos, a escrita reflete ta mbém o acesso do escritor ao arcabouço de produções literárias a que ele/a pôde ter acesso e a maneira como ele/a elabora seu repertório.

Pretendíamos demonstrar ao longo do artigo que a compreensão do conceito de literatura afro-brasileira é ainda fruto de tensões, negociações e embates, como a quantidade de nomenclaturas e definições demonstra. Defendemos, porém, que a maior problemática dessa discussão está na ca tegorização de autoria negra, como procuramos salienta ao longo da exposição, com as citações de pesquisadoras e pesquisadores que trataram da questão. Essa dificuldade está alicerçada no paradoxo das relações raciais brasileiras, fortemente influenciadas pela ideologia da democracia racial e pela história da mestiçagem.

Acreditamos que a afirmação racial dos autores e das autoras, um fator extraliterário, precisa ser tomada como categoria norteadora para a constituição do campo literário afro-brasileiro. Inversamente, contudo, pode-se pensa na identificação de um dado autor com a literatura afro-brasileira a partir de sua textualidade, isto é, a partir dos marcadores formais e estéticos de sua obra, sem que se desvincule de uma corporeidade. Ilustrativos desse processo são os casos de Machado de Assis e Cruz e Souza, autores que parecera m aos olhos de alguns críticos, como Proença Filho (2004), não ter nenhuma relação com a litera tura afro-brasileira, uma vez que trataram em suas obras de personagens brancos e imagens alvas. No entanto, a corporeidade negra desses autores pode ser afirmada a partir de seus textos, os quais formaliza m uma perspectiva crítica da branquitude - ora fazendo dela objeto de ironia (Machado de Assis), ora evidenciando o emparelhamento do negro no universo imagético eurocêntrico (Cruz e Souza).

Ainda que o debate sobre a autoria não esteja encerrado, podemos concluir que o que o termo literatura afro-brasileira contundentemente aponta é o processo de embranquecimento do cânone brasileiro, constituído a partir da ausência e apagamento de escritores negros e escritoras negras. A (auto)a firmação negra e a noção de escrevivência, ou seja, a reivindicação de uma herança e escrita afrodiaspórica atrelada a noções de negritude e identidade negras, funcionam como ferramentas de visibilidade e representatividade literária. Entretanto, e nos parece ser este um ponto crucial no que se refere à noção de literatura afro-brasileira/ negra, não podemos cair na armadilha de 
esquecer que de modo muito significativo o campo literário brasileiro tem utilizado como parâmetro de formação, legitimação e consolidação a branquitude. $\mathrm{O}$ que nos interessa pensar (retomando as palavras de Proença Filho [2004] e Bernd [1987], por exemplo, e a recusa de ambos em "epidermizar" materialidades textua is equacionando “cor da pele" à expressão literária quando a questão é literatura afro-brasileira) é que a epidermização fundamenta as noções e concepções da própria literatura brasileira. A partir de um olhar interseccional crítico é nítido que o que denominamos de literatura brasileira (ou campo literário brasileiro) é fruto de agentes muito específicos, reflexo de tensões e negociações, preconceitos e pré-julgamentos de nossas realidades sociais, históricas e culturais. Conforme nos adverte Dja mila Ribeiro:

O lugar social não determina uma consciência discursiva sobre esse lugar. Porém o lugar que ocupamos socialmente nos faz ter experiências distintas e outras perspectivas. A teoria do ponto de vista feminista e lugar de fala nos faz refutar uma visão universal de mulher e de negritude, e outras identidades, assim como faz com que homens brancos, que se pensam universais, se racializem, entendam o que significa ser branco como metáfora do poder, como nos ensina [Grada] Kilomba. Com isso, pretende-se também refutar uma pretensa universalidade. Ao promover uma multiplicidade de vozes o que se quer, acima de tudo, é quebrar com o discurso autorizado e único, que se pretende universal. Busca-se aqui, sobretudo, lutar para romper com o regime de autorização discursiva. (RIBEIRO, 2017, p. 69-70, grifo nosso).

Nos debates contemporâneos sobre literatura, raça - termo costumeiramente ausente das teorias e críticas literárias, bem como dos manuais canônicos - emerge como parâmetro questionador e desafiador: as vozes negras rompem a máscara do silêncio branco por meio da escrita. Objetivando reinscrever e ressignificar as experiências negras a partir da literatura, presenciamos a proliferação de artigos, ensaios, teses, dissertações e periódicos cujo foco é a literatura de escritores e escritoras negras no Brasil. Retomando a noção de lugar de fala, como definida por Ribeiro (2017), o ponto de vista negro na literatura, promovendo uma multiplicidade de vozes, encoraja a refutação de noções como cânone, tradição, universalidade, apontando que aquilo que comumente se definiu valorativamente como Litera tura Brasileira corresponde à literatura branco-brasileira - publicações feitas majoritaria mente por autores homens, brancos, do eixo Rio-São Paulo, la nçadas por grandes editoras (DALCASTAGNÈ, 2005) e, geralmente, em diálogo com o cânone nacional estabelecido. 
A partir de uma posição de estrangeiro de dentro (outsider within, nos termos de Patricia Hill Collins [2016]), ao mesmo tempo dentro e fora de uma brasilidade e litera riedade, a escrita empreendida por autoras e autores que "se querem negros" possibilita a emergência de diferentes perspectivas no campo da literatura brasileira, indo de encontro a imagens estabelecidas a partir de lugares de fala que se constroem negando uma negritude e, principalmente, performatizando uma posição universal que seria arracializada e agendrada (sem gênero sexual).

No percurso teórico-crítico que fizemos ao longo deste artigo, enfatiza mos ser necessário ter em mente que a discussão sobre produção e campo literário perpassa a discussão sobre autoria - no caso da literatura afro-brasileira, de uma autoria negra, uma voz negra; no caso da literatura branco-brasileira, de um marcador racial (branco) que contraditoriamente se projeta como não-racial e universal, o brasileiro. No entanto, o que nos parece um grande dilema sobre a noção de voz discursiva, materialidade textual e corporeidade é que podemos incidir em um discurso que equaciona textualidade e corporeidades inocentemente. Em uma das muitas entrevistas e ensaios críticos de Conceição Evaristo (2013), a autora reafirma e estabelece os termos a partir dos quais performa sua escrita. A textualidade e materialidade discursiva de seus textos estão em conexão com sua posição de mulher, negra, professora, ex-moradora de favela, mãe e assim por diante. A autora, conscientemente, reivindica um lugar de fala que se percebe como marcado por noções de raça, gênero, sta tus social, classe, profissão e nacionalidade (como o são todos os lugares de fala, segundo a advertência de Dja mila Ribeiro [2017]).

A armadilha, nos parece, está em acreditarmos que Conceição Evaristo, por exemplo, somente seria capaz de produzir literatura objetiva e diretamente relacionada a suas experiências de vida, ou mais do que isso, que ela seria representativa da totalidade da experiência negra feminina no Brasil (o que, em nenhum momento, a autora afirma ou corrobora). Esse é o primeiro ponto - o que significa uma voz negra.

Ao estabelecermos uma correlação exata entre texto e corporeidade, podemos também cair em uma segunda armadilha: todo artista negro produz arte negra (uma arte politicamente engajada). Essa afirmação não é somente incoerente como perniciosa. Quando pensamos em autoria, frisamos dois parâmetros a partir dos quais nos pautamos: a autoafirmação e/ou a (auto)identificação. É de suma importância a autoafirmação do autor e da autora, preocupados em reivindicar um ponto de vista marcado étnico-racialmente, ao estabelecerem os termos com os 
quais se identificam. A noção de literatura afro-brasileira implica refletir sobre um posicionamento crítico, sem que deslegitimemos ou menosprezemos a produção de artistas negros e negras que não se auto-identifica m com o campo da literatura afro-brasileira (como pensado e definido por diversos estudiosos).

A noção de "arte politicamente engajada", muito utilizada como justificativa de não literariedade por uma gama de críticos e teóricos literários, postula mais uma das armadilhas em que facilmente tendemos a cair quanto à noção de cânone e campo literário, porque ela leva a crer que, por oposição, existiria um tipo de arte que é apolítica, descorporificada e, portanto, universal. Essa discussão encontra paralelos em críticas feministas feitas à noção habermasiana de esfera pública, a qual se a mpara numa dualidade entre o que é público e o que é privado, entendendo-se privado como aquilo que pertence ao corpo, à vida doméstica e individual, em contraste com a vida pública, que seria regida pela universalidade e pelo bem comum (MARRA, 2019). Em resumo, a conclusão dessas críticas é que não existe possibilidade de separação entre o privado e o público, havendo, na realidade, a necessidade de desnaturalização do que se entende por universal, bem comum, público, privado. Seguindo esse raciocínio, argumentamos que o campo da literatura canônica é tão dotado de identidade étnico-racial, classe, gênero como qualquer outro, sendo a sua aparente neutralidade o resultado de relações de poder que estabelecem como apolítica certa literatura engajada em termos eurocêntricos, patriarcais e elitistas.

E por último, é válido ponderar que, vivendo em um país racial e etnicamente diverso, facilmente somos levadas/os a acreditar que no Brasil todo mundo é brasileiro de uma mesma e homogênea ma neira, logo, não faria sentido pensarmos em literatura afro-brasileira e nem em autoria negra, pois a assunção de uma negritude poderia ser feita por todas as pessoas, dadas nossas hera nças africanas. $\mathrm{O}$ fator miscigenação, implicado na noção de afro-brasileiro, pode operar como uma "faca de dois gumes", porque ao mesmo tempo que evidencia um componente afro-diaspórico, aparentemente mascara a realidade empírica do racismo estrutural e de vários outros eixos de discriminação e opressão.

Dentre os vários problemas de nossos paradoxos das mestiçagens, não podemos esquecer de processos genocidas e eugenistas de embranquecimento; nem do silenciamento e apagamento da presença negra em nossa mítica e idílica formação nacional; nem da ausência sistêmica de escritoras negras e escritores negros nos grandes manuais de literatura. A autoria negra, do/a autor/a que reivindica 
uma posição marcada étnica e racialmente (ou daquele/a que assim é percebido/a por um dado público), precisa ser lida enquanto contundente argumento questionador e refutador do discurso canônico e universalista da literatura.

Essa reflexão significa também tomar consciência do fator racial como preponderante para a compreensão da racialização das relações sociais e do estabelecimento do cânone literário brasileiro. Quando a utores negros e a utoras negras assumem uma negritude, reivindica m, por um lado, representatividade e visibilidade para suas produções e, por outro, apontam para o racismo estrutural (estruturador e estruturante) do campo da teoria, da crítica e da produção literá ria que continuam a seguir paradigmas eurocêntricos, sem se esquecer dos efeitos fatais desse racismo.

Deve-se destacar que, na literatura dita negra ou afro-brasileira, as imagens do negro circulam com intenções que se marcam pela autoconscientização e pela imposição de ampliar o espaço de visibilidade dos negros e de seus descendentes, independentemente da cor da pele, do tipo de cabelo, ou da carnadura do corpo. (FONSECA, 2011, p. 266)

A a firmação de um sujeito negro consciente e enunciador do discurso estabelece o lugar de fala do autor e os termos a partir dos quais se constroem e se materializam na textualidade literária suas subjetividades e repertórios, os quais passa $\mathrm{m}$ por escrever e reinscrever as experiências afro-diaspóricas a partir de um olhar interno, conferindo espaço à população negra a partir de representações literárias plurais e, consequentemente, tornando mais dinâmica e complexa a experiência da literatura. A escrita negra pode ser, assim, compreendida como a urgência de se erguer a voz contra a lâmina da universalidade e os preceitos de objetividade e neutralidade, demonstrando que a ausência de escritoras negras e escritores negros dos manuais de literatura brasileira significa não inexistência, mas exclusão.

\section{REFERÊNCIAS}

BERND, Zilá. Negritude e literatura na América Latina. Porto Alegre: Mercado Aberto, 1987 988 Introdução à literatura negra. São Paulo: Ed. Brasiliense

Literatura e identidade nacional. 3 ed. Porto Alegre: UFRGS Editora, 2011 [1992].

BROOKSHAW, David. Raça e cor na literatura brasileira. Porto Alegre: Mercado Aberto, 1983. 
COATES, Ta-Nehisi. Preface. IN: MORRISON, Toni. The origin of others. Cambridge; London: Harvard University Press, 2007.

CUTI. (Luiz Silva). Literatura negra brasileira: notas a respeito de condicionamentos. IN: QUILOMBHOJE (Org.). Reflexões sobre literatura afro-brasileira. São Paulo: Conselho de Participação e desenvolvimento da Comunidade Negra, 1985. p. 15-24. 2010

Literatura negro-brasileira. São Paulo: Selo Negro,

DAMASCENO, Benedita Gouveia. Poesia negra no modernismo brasileiro. Campinas: Pontes, 1988.

DALCASTAGNÈ, Regina. A personagem do romance brasileiro contemporâneo: 1990-2004. Estudos de Literatura Brasileira Contemporânea, Brasília, n. 26, p. 13-71, jul./dez. 2005.

DUARTE, Eduardo de Assis. Literatura Afro-brasileira: um conceito em construção. In: AFOLABI, Niyi; BARBOSA, Márcio; RIBEIRO, Esmeralda (Org.). A mente afro-brasileira. Trenton; Asmara: Africa World Press, 2007, p. 103-112. Disponível em: < https:// social.stoa.usp.br/articles/0037/3053/Literatura Afro-brasileira EDUARD0.pdf > . Acesso em: 20 jun. 2019

Machado de Assis afro-descendente. Rio de Janeiro Belo Horizonte: Pallas/Crisálida, 2009.

(Org.). Literatura e afro-descendência no Brasil: antologia crítica. Belo Horizonte: Editora UFMG, 2011-2014. 4 v.
EVARISTO, Conceição. Da grafia desenho de minha mãe: um dos lugares de nascimento de minha escrita. In: ALEXANDRE, M. A (Org.). Representações performáticas brasileiras: teorias, práticas e suas interfaces. Belo Horizonte: Mazza Edições, 2007. p 16-21.

Escrevivências da afro-brasilidade: história e memória. Releitura, Belo Horizonte, n. 23, 2008

Literatura negra: uma voz quilombola na literatura brasileira. In: PEREIRA, Edmilson de Almeida (Org.). Um tigre na floresta de signos: estudos sobre poesia e demandas sociais no Brasil. Belo Horizonte: Mazza, 2010. p. 132-142.

FISCH, Audrey (Ed.). The Cambridge Companion to African American Slave Narratives. Cambridge: Cambridge University Press, 2007.

FONSECA, Maria Nazareth Soares. Literatura negra, os sentidos e as ramificações. IN: DUARTE, E. A; FONSENCA, M. N. Literatura e afro-descendência no Brasil: antologia crítica. Editora UFMG: Belo Horizonte, 2014. vol. 4 (História, teoria, polêmica). p. 245277. Disponível em: <http://www.letras.ufmg.br/literafro/artigos/ artigos-teorico-conceituais/159-maria-nazareth-soares-fonseca-literatura-negra-os-sentidos-e-as-ramificacoes > . Acesso em: 20 jun. 2019.

GOULD, Philip. The Rise of the Slave Narrative. In: FISCH, Audrey. The Cambridge Companion to the African American Slave 
Narrative. Cambridge: Cambridge University Press, 2007. p. 11-27.

MARRA, Laísa. Esferas públicas em conflito: contribuições de Nancy Fraser ao conceito de esfera pública. Revista Ideação, Feira de Santana, v. 1, n. 40, p. 210-219. Disponível em: <http://periodicos.uefs.br/index.php/revistaideacao/article/view/4591/4187> . Acesso em: 20 maio 2020.

MORRISON, Toni. The origin of others. Cambridge; London: Harvard University Press: 2007.

MÜLLER, Tânia M. P.; CARDOSO, Lourenço. Branquitude: estudos sobre a identidade branca no Brasil. Curitiba: Appris Editora, 2017.

PEREIRA, Edimilson de Almeida. Territórios cruzados: relações entre cânone literário e literatura negra e/ou afro-brasileira. IN PEREIRA, E. A; DAIBERT Jr, Robert. (Org.). Depois, o Atlântico: modos de pensar, crer e narrar na diáspora africana. Juiz de Fora: Editora UFJF, 2010. p. 319-349. Disponível em: < http://www.letras.ufmg.br/literafro/artigos/artigos-teorico-conceituais/1035-territorios-cruzados-relacoes-entre-canone-literario-e-literatura-negra-e-ou-afro-brasileira1 > . Acesso em: 20 jun. 2019.

PROENÇA FILHO, Domício. A trajetória do negro na literatura brasileira. Estudos Avançados, São Paulo, v. 18, n. 50, p. 161-193, 2004
RIBEIR0, Djamila. 0 que é: lugar de fala? Belo Horizonte: Letramento - Justificando, 2017.

ROGRIGUES, Fabiane Cristine. Quilombos editoriais. Opiniães, Revista de Alunos de Literatura Brasileira, São Paulo, n. 10, p. 103-111, 2017. Dossiê:: Presença Negra na Literatura Brasileira. Disponível em: < http://www.revistas.usp.br/opiniaes/article/ view/122413/132981 > . Acesso em: 02 mar. 2020.

SILVA, Priscila Elisabete da. 0 conceito de branquitude: reflexões para o campo de estudo. In: MÜLLER, Tânia M. P.; CARDOSO, Lourenço. Branquitude: estudos sobre a identidade branca no Brasil. Curitiba: Appris Editora, 2017

SOUZA, Florentina da Silva. Afro-descendência em Cadernos Negros e Jornal do MNU. Belo Horizonte: Autêntica, 2006.

WARE, Vron. (Org.). identidade branca e multiculturalismo. Trad. Vera Ribeiro. Rio de Janeiro: Garamond, 2004.

Recebido em: 27-11-2019.

Aceito em: 29-02-2020 